\title{
PREPARATION AND CHARACTERIZATION OF DIALDEHYDE 2, 3-DIAMINOPYRIDINE STARCH CHELATING POLYMER AND ITS SORPTION POTENTIAL FOR CD(II), CU(II) AND NI(II) IONS IN AQUEOUS MEDIA
}

Danjani A. G., Salisu* A. A. and Usman A. H.

Department of Pure and Industrial Chemistry, Bayero Unuversity Kano, Nigeria Corresponding author: aasalisu@yahoo.com

\begin{abstract}
Dialdehyde cassava starch (DAS) was prepared and characterized. Polymeric chelating ligands containing 2,3-diaminopyridine have been prepared from dialdehyde starch, the removal of copper(II), nickel(II) and cadmium(II) ions from aqueous solutions by dialdehyde 2,3diaminopyridine starch (DAS2,3-DNH $\mathrm{N}_{2}$ PYR) was investigated. The adsorbent degree of substitution (DS) 0.82 was characterized by solubility test, Fourier Transform Infrared spectroscopy (FT-IR), elemental analysis, and Scanning Electron Microscopy (SEM). Batch adsorption has been performed to identify the binding property of metal (ii) ions. The maximum adsorption capacity was found to be $31.1 \mathrm{mg} / \mathrm{g}$ for cadmium and nickel, $30 \mathrm{mg} / \mathrm{g}$ for copper, and removal efficiency was $78 \%, 77.77 \%$ and $75 \%$ for cadmium, nickel and copper respectively. Polymeric chelating ligand could therefore be used to remove the metals from aqueous solution. Keywords: Starch Polymer, Dialdehyde starch, Starch 2, 3-Aminopyridine, Chelating resin.
\end{abstract}

\section{INTRODUCTION}

Heavy metals are highly toxic and can cause damaging effects even at very low concentrations. They tend to accumulate in the food chain and in the body and can be stored in soft (e.g., kidney) and hard tissues (e.g., bone). Being metals, they often exist in a positivelycharged form and can bind on to negatively-charged organic molecules to form complexes. Heavy metals are originating from various industrial activities, such as agriculture, mining, and combustion of fossil fuels, waste disposal, battery manufacture, and petroleum refining. These heavy metals are non-biodegradable, can accumulate in internal organs, and cannot be utilized by living organisms, thus causing various problems and disorders (An et al., 2015), therefore they must be removed before discharge. Common techniques for removal of heavy metals from aqueous solutions are chemical precipitation, adsorption, ion exchange, electrolysis, coagulation and membrane separation (Namasivayam and Ranganathan, 1995). However, most of these techniques have several disadvantages such as production of secondary pollution, high cost, high levels of energy involved, chemicals needed, and weak treatment operation at low metal ion concentrations (Feizi and Jalali, 2015). Chemical precipitation is only optimal for high heavy metal ion concentration in wastewater and ion-exchange may cause secondary contamination when resins are regenerated by chemical reagents. Similarly, membrane filtration has drawbacks such as cost inefficiency and fouling, while flotation is costly (Fu and Wang, 2011). Research interest into the production of cheaper adsorbents to replace these costly wastewater treatment methods are attracting attention of scientists (Feizi and Jalali, 2015).

Adsorption technique has received much attention because it allows the use of many materials that are environmental friendly and have low production cost (Cegłowski and Schroeder, 2015).

Adsorption studies on the natural polysaccharide, adsorbents based on starch and other low cost materials have become a focus of study in the removal of heavy metals such as wheat shells (Basci et al., 2003), sweet potato starch (Fang et al., 2004), wheat bran (Farajzadeh and Monji, 2004), starch and chitin (Crini, 2005), tea leaves (Ahluwalia and Goyal, 2005), pulping wastes (Celik and Demirbas, 2005), wood based adsorbent (Argun and Dursun, 2006), okra (Hashem, 2007), succinylated starch (Awokoya and Moronkola, 2012), chitosan (Monier et al., 2012), corn starches
(Awokoya and Moronkola, 2013), jujube (An et al., 2015), porous starch (Ma et al., 2015), potato starch (Feizi and Jalali, 2015) e.t.c. Some of the advantages of using these polysaccharide materials for wastewater treatment include simple technique, requires little processing, good adsorption capacity, selective adsorption of heavy metal ions, low cost, free availability and easy regeneration.

Several chemicals with certain functional groups have been attached through the aldehyde group of the dialdehyde starch to form Schiff base and hence making it chelating polymer. The amino group normally acts as a reactive site for the formation of Schiff base. Polymers that possess Schiff bases in their structure make an important group of chelating activity. Schiff bases that are built of nitrogen and oxygen donor atoms, are well known for their very good selectivity towards complexation of transition metals ions, and low affinity to alkali and alkaline earth metal ions (Cegłowski and Schroeder, 2015).

Chelating polymers possess functional groups that comprise one or more donor atoms acting as ligands towards certain types of cations. These polymers usually show higher selectivity to metal cations than ionic polymers, they are therefore been used for the uptake of heavy metals (Bessbousse et al., 2010; Bessbousse et al., 2012; Fan et al., 2013; Sun et al., 2011; Xiong and Yao, 2009; Yang et al., 2011).

In the present work, we prepared a chelating polymer by reacting dialdehyde starch with 2,3-diaminopyridine to form the Schiff base (DAS2,3-DNH ${ }_{2}$ PYR) and used it to adsorb $\mathrm{Cu}(\mathrm{II}), \mathrm{Cd}(\mathrm{II})$ and $\mathrm{Ni}(\mathrm{II})$ ions in a batch system. Percentage of the removal and adsorption capacity of the novel Schiff base were investigated.

\section{Materials and method}

Materials

Native cassava starch was extracted from cassava tubers obtained from Janguza Market, Kano, Nigeria. Potassium periodate (xilong chemical co. Itd), 2,3diaminopyridine $98 \%$, Sodium hydroxide, phenolphthalein, Dimethyl sulphoxide (DMSO), Dimethylformamide (DMF), ethanol, hexane, chloroform, acetone, methanol $99.8 \%$, sodium acetate, sulfuric acid were obtained from Sigma-Aldrich chemical co. Itd and were of Analytical Grade. Scanning electron microscope (SEM) and energy dispersive X-ray spectroscopy (Phenom ProX) was used to obtain the Photomicrographs and elemental analysis, FTIR Spectra was obtained from infrared spectrophotometer Cary360 (Agilent Technologies). 
All glassware and plastic containers used were washed with detergent solution, rinsed with tap water and finally with distilled wa

\section{MATERIALS AND METHODS}

\section{Preparation of dialdehyde starch and} determination of aldehyde content

Dialdehyde starch was prepared according to the method described in the literature (Yin et al., 2008). $200 \mathrm{~cm}^{3}$ Potassium periodate solutions $(0.25 \mathrm{~mol} / \mathrm{L}, 0.50$ $\mathrm{mol} / \mathrm{L}$ and $0.75 \mathrm{~mol} / \mathrm{L}$ ) used as oxidant were added into three different beakers containing $20 \mathrm{~g}$ of pure dried cassava starch to prepare dialdehyde starch. The mixture was stirred slowly at $30{ }^{\circ} \mathrm{C}$ in the dark for $8 \mathrm{hrs}$ and washed three times with distilled water and ethanol. Three samples with different degrees of oxidation were defined as DAS-A, DAS-B and DAS-C. The aldehyde group content was determined using the rapid quantitative alkali consumption method (Hofreiter et al., 1955) and the results were $67.62 \%, 50.72 \%$ and $37.38 \%$ for DAS-A, DAS-B and DAS-C, respectively.

Determination of average molecular weight of dialdehyde starch

The determination of average molecular weight (Mw) of dialdehyde starch was based on the measurement of intrinsic viscosity [ $\eta$ ] and the measurements were carried out in triplicate at $25.0 \pm 0.2^{\circ} \mathrm{C}$ with an Ubbelohde Viscometer (capillary tube with $0.58 \mathrm{~mm}$ in diameter) inside a temperature controlled water bath. The samples were dissolved in DMSO, and several concentrations of $0.12 \mathrm{M}, 0.14 \mathrm{M}, 0.16 \mathrm{M}, 0.18 \mathrm{M}$ and $0.20 \mathrm{M}$ of dialdehyde starch were prepared from $0.025 \mathrm{~L}$ of Dimethyl sulfoxide (DMSO).

\section{Preparation of Dialdehyde starch 2, 3-} diaminopyradine (DAS2,3-DNH ${ }_{2}$ PYR)

The Schiff bases were prepared according to the method described by Fu, F., and Wang, Q. (2011). DAS slurry was prepared from $4 \mathrm{~g}$ dry DAS-A and $100 \mathrm{~cm}^{3}$ distilled water in a $250 \mathrm{~cm}^{3}$ three-necked flask and $8 \mathrm{~g}$ of 2,3-diaminopyridine was added, the mixture was stirred with a magnetic stirrer in a thermostat water bath at $50^{\circ} \mathrm{C}$ under nitrogen. The $\mathrm{pH}$ of the solution was adjusted to 5.0 by adding sodium acetate buffer. The reaction was carried out at $50^{\circ} \mathrm{C}$ and 4 hours. The resulting solid was separated from solution by filtration and washed three times with distilled water $\left(3 \times 100 \mathrm{~cm}^{3}\right)$, then dried at $50^{\circ} \mathrm{C}$ to a constant weight.

\section{Sorption experiment}

The sorption experiment was carried out in $100 \mathrm{~cm}^{3}$ conical flasks containing the desired doses of DAS2,3$\mathrm{DNH}_{2}$ PYR and $50 \mathrm{~cm}^{3}$ each of $\mathrm{CdCl}_{2}, \mathrm{Cu}(\mathrm{Ac})_{2}$ and $\mathrm{Ni}(\mathrm{Ac})_{2}$ solution. The initial concentration of the metal solutions was $100 \mathrm{mg} / \mathrm{l}$ and the initial $\mathrm{pH}$ of the metals was adjusted to 6.0 with $0.1 \mathrm{M} \mathrm{NaOH}$ before adding the adsorbent. After shaking for a certain time, the mixture was centrifuged and filtered. The final concentration of $\mathrm{Cu}$ (II), Cd(II) and $\mathrm{Ni}(\mathrm{II})$ ions were determined by atomic adsorption spectrophotometer (AAS) (Fan et al., 2013).

\section{Solubility test}

All the polymeric complexes were tested for their solubilities in water and some organic solvents by dissolving the sample in each solvent at room temperature. The solubility of the samples was recorded and given in Table 4.

\section{Results and discussion}

The synthetic reaction routes for the intermediate and final compounds Schiff base $\mathbf{3}$ and the metal Schiff base complex $\mathbf{4}$ are presented in scheme I. Native cassava starch $\mathbf{1}$ was treated with sodium periodate $\left(\mathrm{NaIO}_{4}\right)$ to give dialdehyde starch DAS $\mathbf{2}$ and the dialdehyde starch DAS was subsequently treated with 2, 3-diaminopyridine to produced dialdehyde starch 2, 3-diaminopyridine (DAS2,3-DNH ${ }_{2}$ PYR) cross linked polymer material 3.

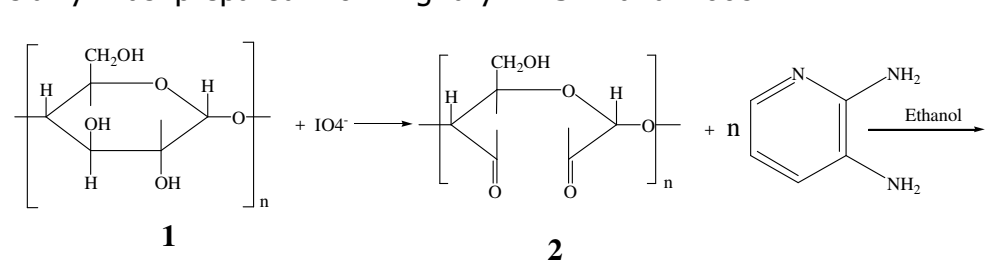

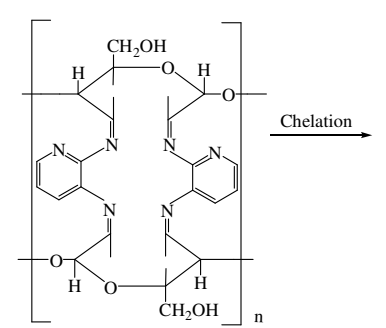

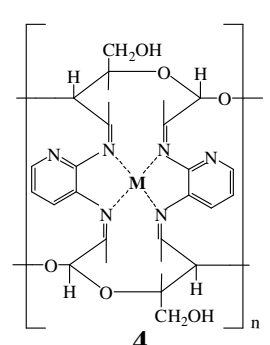

Scheme 1: Procedure for the preparation of the Schiff base

The dialdehyde starch 2, 3-diaminopyradine Schiff's base as ligand was further reacted with metal chlorides to yield dialdehyde starch 2, 3-diaminopyridine Schiff base metal chelates $\mathbf{3}$ as shown in scheme $\mathbf{1}$ above.

\section{Content of the aldehyde groups of DASs}

The Cassava starch was oxidized by potassium periodate to form DAS and the percentage of dialdehyde units was obtained from equation 1

$$
=\frac{\left(\mathrm{C}_{2} \mathrm{v}_{1}-2 \mathrm{C}_{2} \mathrm{v}_{2}\right)}{w / 161} 100 \% \text { Da\% }
$$

Where: $V_{1}$ and $V_{2}$ represent the total volumes $(L)$ of $\mathrm{H}_{2} \mathrm{SO}_{4}, \mathrm{NaOH}$ respectively while, w is the dry weight (g) of the oxidized starch. $\mathrm{C}_{1}$ and $\mathrm{C}_{2}$ ( $\mathrm{mol} / \mathrm{l}$ ) represent the concentrations of $\mathrm{H}_{2} \mathrm{SO}_{4}$ and $\mathrm{NaOH} .161$ is the average molecular weight of the repeated unit in dialdehyde starch.

The volume of acid used in calculating percentage of aldehyde was given in Table 1 . The contents of the aldehyde groups, which reflect the degree of oxidation, were expressed as the number of carbonyl groups per 100 units.

Table 1: Titration result

\begin{tabular}{|c|c|c|c|c|}
\hline DAS & $1^{\text {st }}$ Reading $\left(\mathrm{cm}^{3}\right)$ & $2^{\text {nd }}$ Reading $\left(\mathrm{cm}^{3}\right)$ & $3^{\text {rd }}$ Reading $\left(\mathrm{cm}^{3}\right)$ & Volume of acid \\
\hline DAS-A & 24.60 & 24.80 & 24.70 & $24.60+24.80+24.70 / 3=24.70$ \\
\hline DAS-B & 26.30 & 26.20 & 26.40 & $26.30+26.20+26.40 / 3=26.30$ \\
\hline DAS-C & 28.50 & 28.40 & 28.30 & $28.50+28.40+28.30 / 3=28.40$ \\
\hline
\end{tabular}

The contents of the aldehyde groups of DAS increased with higher ratios of potassium periodate to cassava starch. The contents of the aldehyde groups for DAS-A, DAS-B, DAS-C were as follows: $67.62 \%, 50.72 \%$ and $37.38 \%$, respectively. The reason could be that, when the molar ratio of potassium periodate to cassava starch increased, the superfluous oxidant degraded the starch and caused some of the DAS to dissolve in the water, resulting in a reduced DAS yield (Fiedorowicz and Para, 2006). Another reason could be that starch is known to have a tendency to hydrolyze at $\mathrm{pH}$ lower than 7.0, and this will be accelerated by lower $\mathrm{pH}$ and oxidant concentration (Zhang et al., 2007).

\section{Average molecular weight of DAS}

The average molecular weight of the polymers was obtained according to Mark-Houwink equation given in equation $\mathbf{2}$ and results were presented in Table 2.

$$
[\mathrm{n}]=\mathrm{KM}^{\mathrm{a}}
$$


Where $[\eta]=$ Intrinsic Viscosity, $\mathrm{K}$ and $\mathrm{a}$ are constants given as $8.5 \times 10^{-3}, \mathrm{ml} / \mathrm{g}$ and 0.76 , respectively and $\mathrm{M}$ is the molecular weight (Zhang et al., 2011).The molecular weight of DAS decreases drastically when dialdehyde starch was prepared by the use of potassium periodate under acidic condition. DAS with the content of the aldehyde groups of $37.38 \%$ had an average molecular weight of about 97,016 , DAS-B $(50.72 \%)$ had an average molecular weight of 17,044 , when the content of the aldehyde groups increased to $67.62 \%$ the molecular weight of DAS was 9,820 and for the native cassava starch was about 861,800 respectively.

Table 2. Viscosity Average molecular weight

\begin{tabular}{|c|c|c|c|c|c|c|c|c|c|c|c|c|c|}
\hline \multirow{2}{*}{$\begin{array}{l}\text { Conc. } \\
(\mathrm{mol} / \mathrm{l})\end{array}$} & \multicolumn{4}{|c|}{$\mathrm{T}$} & \multirow[t]{2}{*}{$t_{0}$} & \multicolumn{4}{|c|}{$\eta s p=\frac{t-t_{0}}{t_{0}}$} & \multicolumn{4}{|c|}{ Reduced viscosity ( $\eta \mathrm{sp} / \mathrm{c}$ ) } \\
\hline & $\begin{array}{l}37.83 \\
\%\end{array}$ & $\begin{array}{l}50.72 \\
\%\end{array}$ & $\begin{array}{l}67.62 \\
\%\end{array}$ & $\begin{array}{l}\text { Native } \\
\text { starch }\end{array}$ & & $\begin{array}{l}37.83 \\
\%\end{array}$ & $\begin{array}{l}50.72 \\
\%\end{array}$ & $\begin{array}{l}67.62 \\
\%\end{array}$ & $\begin{array}{l}\text { Native } \\
\text { starch }\end{array}$ & $\begin{array}{l}37.83 \\
\%\end{array}$ & $\begin{array}{l}50.72 \\
\%\end{array}$ & $\begin{array}{l}67.62 \\
\%\end{array}$ & $\begin{array}{l}\text { Nativ } \\
\mathrm{e} \\
\text { starc } \\
\mathrm{h}\end{array}$ \\
\hline 0.12 & 201 & 59 & 50 & 854 & 22 & 8.16 & 1.70 & 1.18 & 37.8 & 68 & 14.2 & 9.9 & 315 \\
\hline 0.14 & 234 & 67 & 55 & 1023 & 22 & 9.66 & 2.01 & 1.41 & 45.5 & 69 & 14.4 & 10.1 & 325 \\
\hline 0.16 & 236 & 74 & 58 & 1184 & 22 & 9.76 & 2.36 & 1.64 & 52.8 & 61 & 14.8 & 10.3 & 330 \\
\hline 0.18 & 268 & 82 & 63 & 1368 & 22 & 11.16 & 2.70 & 1.98 & 61.2 & 62 & 15.0 & 11.0 & 340 \\
\hline 0.20 & 304 & 89 & 69 & 1562 & 22 & 12.80 & 3.02 & 2.12 & 70.0 & 64 & 15.1 & 10.6 & 350 \\
\hline
\end{tabular}

Similar observation has been reported (Fiedorowicz and Para, 2006; Zhang et al., 2007). The reason for this could be that, when $\mathrm{KIO}_{4}$ cleaved the $\mathrm{C} 2-\mathrm{C} 3$ bonds of the glucose units of cassava starch, the oxidation also led to disruption of both a- D-(1-4) and a-D-(1-6) glucosidic bonds which causes the average molecular weight of dialdehyde starch to decline drastically (Fiedorowicz and Para, 2006). The molecular weight of DAS as a function of carbonyl content, concentrations of the polymer solutions and that of the pure solvent and, the reduced viscosity are shown in Table 2 above.

Degree of substitution, adsorption capacity and removal efficiency

The degree of substitution (DS) of 2,3-diaminopyridine for DAS2,3-DNH ${ }_{2}$ PYR was theoretically calculated from the nitrogen content with the following equation $\mathbf{3}$.

$$
\mathrm{DS}=\frac{161 \mathrm{xN} \%}{(28) 100-109 \cdot 13 \mathrm{xN} \%}-
$$

Where, N\% was obtained from the elemental analysis, 28 is the molecular mass of $\mathrm{N}_{2}, 109.13 \mathrm{~g} / \mathrm{mol}$ is the molecular weight of 2,3-diaminopyridine. The metal concentration $(\mathrm{mg} / \mathrm{g})$ retained on the adsorbent phase $(q e)$ and the removal efficiency (\%) of the adsorbent preparations were calculated using the following equations $\mathbf{4}$ and $\mathbf{5}$ respectively (Gaya et al., 2015).

$$
\mathrm{qe}=\frac{\left(\mathrm{Co}_{0}-\mathrm{Cos}_{\mathrm{e}} \mathrm{v}\right.}{\mathrm{m}}
$$

$$
\text { R100 Removal efficiecy }(\%)=\frac{(\mathrm{Co}-\mathrm{Ce})}{\mathrm{C}_{0}}
$$

Where: $\mathrm{Co}$ is initial concentration of the metal, $\mathrm{Ce}$ is the final concentration of the metal, $v=$ volume of the adsorption solution $(\mathrm{L})$ and $\mathrm{m}=$ dose of the adsorbent (g). The degree of substitution (DS) of 2,3-

\begin{tabular}{|c|c|c|c|c|c|c|c|c|c|c|}
\hline \multirow[t]{2}{*}{ Schiff base } & \multirow[t]{2}{*}{ DS } & \multicolumn{3}{|c|}{$\begin{array}{c}\text { Adsorption Capacity } \\
\qquad \mathrm{q}_{\mathrm{e}}=\frac{\mathrm{Ca} \cdot \mathrm{Cs} / \overline{ }}{m}\end{array}$} & \multicolumn{3}{|c|}{$\begin{array}{l}\text { Removal Efficiency } \\
\text { R.E }=\frac{C_{0} \cdot C_{e}}{c_{o}} 100 \%\end{array}$} & \multicolumn{3}{|c|}{ Elemental Analysis } \\
\hline & & $\mathrm{Cd}$ & $\mathrm{Cu}$ & $\mathrm{Ni}$ & $\mathrm{Cd} \%$ & Cu\% & $\mathrm{Ni} \%$ & N\% & C\% & $\mathrm{H} \%$ \\
\hline DAS2,3-DNH ${ }_{2}$ PYR & 0.82 & $31.1 \mathrm{mg} / \mathrm{g}$ & $30.0 \mathrm{mg} / \mathrm{g}$ & $31.1 \mathrm{mg} / \mathrm{g}$ & 78 & 75 & 77.77 & 9.2 & 53.7 & 6.9 \\
\hline
\end{tabular}
diaminopyridine for DAS2,3-DNH 2 PYR, Removal efficiency and elemental analyses were presented in Table 3
The DS of 2,3-diaminopyridine which represented the average molecular number of the repeat unit in dialdehyde starch 2,3-diaminopyridine was 0.82 . The Schiff base dialdehyde starch 2,3-diaminopyridine successfully reacted with the metal ions (copper(ii), cadmium(ii) and nickel(ii)) to form polymeric complexes as given in scheme $\mathbf{1}$. One of the factors that affect adsorption capacity of metal ions is the acidity of solutions because $\mathrm{H}^{+}$ions compete with the metal cations for the binding sites on the Schiff base. The adsorption experiment was performed at $\mathrm{pH}$ of 6.0 and the adsorption capacity for $\mathrm{Cd}(\mathrm{II}), \mathrm{Cu}(\mathrm{II})$ and $\mathrm{Ni}(\mathrm{II})$ ions were $31.1 \mathrm{mg} / \mathrm{g}, 30 \mathrm{mg} / \mathrm{g}$ and $31.1 \mathrm{mg} / \mathrm{g}$ and removal efficiencies were $78 \%, 75 \%$ and $77.77 \%$ respectively as given in Table 3.

\section{Solubility test}

The prepared cross linked polymer complexes were tested for solubility in water and some common organic solvents.

Table 4: Solubility Test

Table 4: Solubility Test
\begin{tabular}{|l|l|l|l|l|l|l|l|}
\hline Solvent & Chloroform & DMF & DMSO & Ethanol & Hexane & Methanol & Water \\
\hline Solubility & SS & S & S & SS & IS & SS & SS \\
\hline
\end{tabular}

$\mathrm{S}=$ Soluble, $\mathrm{SS}=$ slightly soluble, IS=Insoluble

The complexes are soluble in DMSO and DMF, and slightly soluble in water, methanol, chloroform and ethanol but insoluble in hexane. Similar observation was reported in the Preparation and characterization of dialdehyde starch and its ' cross-linking with copper (II) ion (Salisu et al., 2013).

\section{The FT-IR spectra}

The FT-IR spectra of the native cassava starch and products were detected using infrared spectrophotometer $\left(4000-650 \mathrm{~cm}^{-1}\right)$. Fig. 1 shows the IR spectra of native cassava starch, DAS, DAS2,3-DNH ${ }_{2}$ PYR and the three polymeric complexes of copper, cadmium and nickel. In the spectrum of native cassava starch, it was evident that the characteristic broad band at $3291 \mathrm{~cm}^{-1}$ is assigned to O-H stretching which is due to hydrogen bonding involving the hydroxyl groups on starch molecules. The band at $2931 \mathrm{~cm}^{-1}$ is assigned to $\mathrm{CH}_{2}$ symmetrical stretching vibrations. 
The bands at 1639 and $1423 \mathrm{~cm}^{-1}$ are attributed to the scissoring of two $\mathrm{O}-\mathrm{H}$ bonds of water and $\mathrm{CH}_{2}$ scissoring vibration, respectively (Mano et al., 2003). The bands at 864 and $763 \mathrm{~cm}^{-1}$ are due to skeletal stretching vibrations of starch (Fang et al., 2004). Fig 2. showed the effect of content of the aldehyde groups on spectra of DAS. The DAS of high content of the aldehyde groups (DAS-A) showed a very sharp peak at $1734 \mathrm{~cm}^{-1}$, which is the most characteristic band of $\mathrm{C}=\mathrm{O}$ vibrations in aldehyde groups.

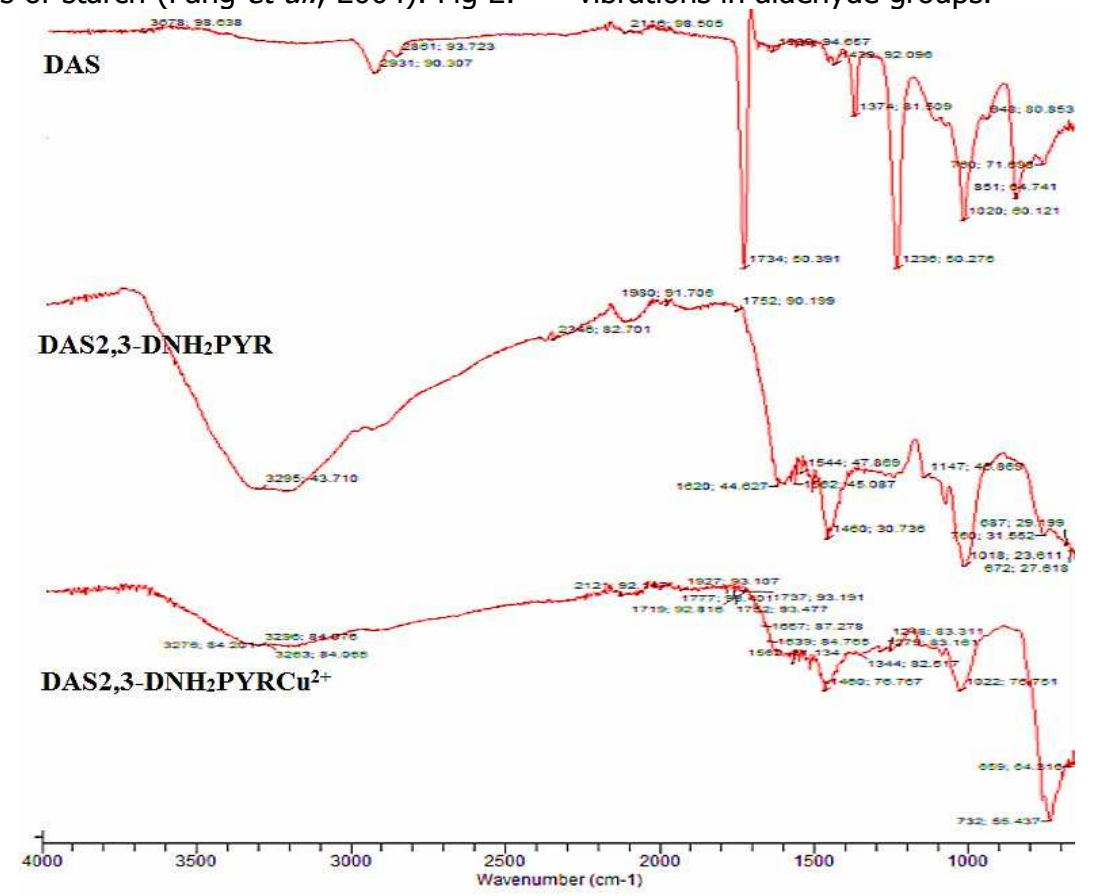

Fig. 1: FT-IR spectra of DAS, DAS2,3-DNH ${ }_{2}$ PYR and DAS2,3-DNH ${ }_{2} \mathrm{PYRCu}^{2+}$

There was a new strong absorption peak at $1640 \mathrm{~cm}^{-1}$ in the spectrum of $\mathrm{DAS2}, 3-\mathrm{DNH}_{2} \mathrm{PYR}$, this bands can be assigned to the $\mathrm{C}=\mathrm{N}$ stretching vibrations of the imine group which indicated the new generation of carbonnitrogen double bond, confirming the formation of Schiff bases between 2,3-diaminopyridine and dialdehyde starch. An intense band at $1460 \mathrm{~cm}^{-1}$ corresponding to the $\mathrm{C}=\mathrm{N}$ stretching of the 2,3-diaminopyridine ring. After adsorption, new bands appeared at $672 \mathrm{~cm}^{-1}$, $732 \mathrm{~cm}^{-1}$, and $672 \mathrm{~cm}^{-1}$ in DAS2,3-DNH ${ }_{2}$ PYRCd $^{2+}$,
DAS2,3-DNH ${ }_{2} \mathrm{PYRCu}^{2+}$ and DAS2,3-DNH ${ }_{2} \mathrm{PYR} \mathrm{Ni}^{2+}$ spectra respectively, these bands were assigned to $\mathrm{M}-\mathrm{N}$ bond and confirming the formation of the polymeric complexes (Salisu et al., 2013 and Feizi and Jalali 2015).

\section{Surface morphology}

The SEM photomocrographs Fig. 2 clearly showed the structure of different samples (native cassava starch, DAS, DAS2,3-DNH 2 PYR, DAS2,3-DNH ${ }_{2}$ PYRCd $^{2+}$, DAS2,3$\mathrm{DNH}_{2} \mathrm{PYRCd}^{2+}$ and $\mathrm{DAS} 2,3-\mathrm{DNH}_{2} \mathrm{PYR} \mathrm{Ni}^{2+}$ ).

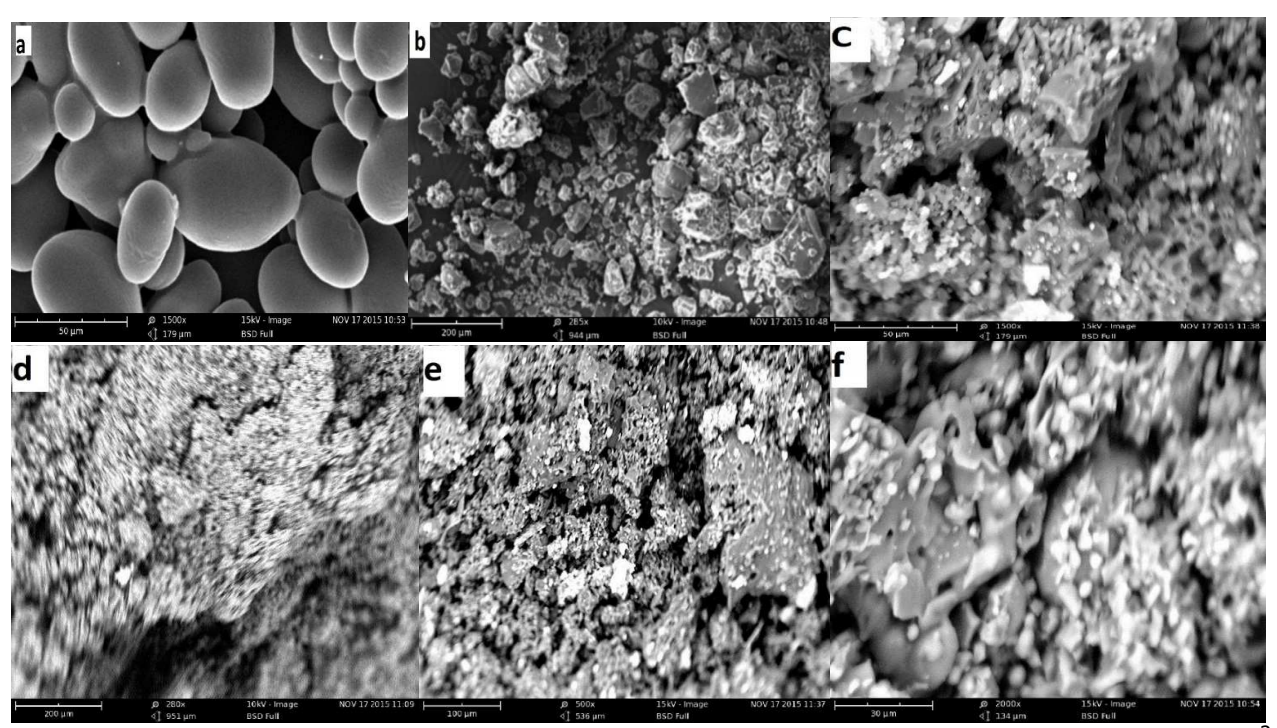

Fig. 2: Photomicograph of (a)Native cassava starch (b)DAS (c)DAS2,3-DNH ${ }_{2}$ PYR(d)DAS2,3-DNH 2 PYR-Cd ${ }^{2+}$ (e)DAS2,3$\mathrm{DNH}_{2}$ PYR-Cd $^{2+}(\mathrm{f})$ DAS2, $3-\mathrm{DNH}_{2} \mathrm{PYR} \mathrm{Ni}^{2+}$ )

It can be seen that the surfaces of the native cassava starch particles (Fig. 2a) is smooth, however, the cleavage of glucosidal rings for particles oxidized by periodate produced and led to uneven surface, and created pores on the particles (Fig. 2b). Furthermore, the particles were conglomerated closely, and the granules became much bigger than the original starch. Connecting with 2,3-diaminopyridine (Fig. 2c), the particles fragments and the irregular structure appeared due to reduction or loss of cross-linking. After the absorption of $\mathrm{Cd}(\mathrm{II}), \mathrm{Cu}(\mathrm{II})$ and $\mathrm{Ni}(\mathrm{II})$ ions (Fig. $2 \mathrm{~d}$, e and f), however the fragments became much smaller.

\section{Conclusion}

This study indicated the suitability of using dialdehyde 2,3-diaminopyridine starch for the uptake of copper, cadmium and nickel ions in aqueous solution by adsorption process. The maximum adsorption capacities of dialdehyde 2,3-diaminopyridine (DAS-2,3DNH2PYR) for $\mathrm{Cd}(\mathrm{II}), \mathrm{Cu}(\mathrm{II})$ and $\mathrm{Ni}(\mathrm{II})$ ions are $31.1 \mathrm{mg} / \mathrm{g}, 30 \mathrm{mg} / \mathrm{g}$ and $31.1 \mathrm{mg} / \mathrm{g}$ and removal efficiencies are $78 \%, 75 \%$ and $77.77 \%$ respectively. The removal of these metal ions was performed at $\mathrm{pH}$ of 6.0 , the adsorption behavior was dependent on the $\mathrm{pH}$ of the solution and initial concentration of the metal ions. DAS-2,3DNH2PYR is therefore an effective low-cost adsorbent for the removal of cadmium, copper and nickel ions from aqueous solution. 


\section{REFERENCES}

Ahluwalia, S. S., and Goyal, D. (2005) Removal of heavy metals from waste tea leaves from aqueous solution. J eng.\& life sci., 5, 158-162

An, B., Lee, C., Song, M., Ryu, J., Lee, S., Park, S., (2015) Applicability and toxicity evaluation of an adsorbent based on jujube for the removal of toxic heavy metals. J. react. func polym., 93, 138-147.

Argun, M. E., and Dursun, S. (2006) Removal of heavy metal ions using chemically modified adsorbents, Intern. J. env. appln. \& Sci., 2(1), 27-40

Awokoya, K. N., and Moronkola, B. A. (2012) Preparation and characterization of succinylated starch as adsorbent for the removal of $\mathrm{Pb}$ (II) ions from aqueous media. Intern. J. Eng. \& Sci., 1(11), 18-24.

Awokoya, K. N., and Moronkola, B. A. (2013) 2, Amino4,6-dihydroxylpyrimidine modified corn starches for uptake of $\mathrm{Cu}$ (II) ions from aqueous media. Intnl j. eng \& sci., 2(5), 49-55.

Basci, N., Kocadagistan, E., and Kocadagistan, B. (2003) Biosorption of $\mathrm{Cu}$ (II) ion from aqueous solutions by wheat shells, J. Desaln.,164, 135140.

Bessbousse, H., Rhlalou, T., Verchere, J. F., and Lebrun, L. (2010). Mercury removal from wastewater using a poly(vinylalcohol)/poly(vinylimidazole) complexing membrane. J. Chem. Eng., 164, 37-48

Bessbousse, H., Verchere, J. F., and Lebrun, L. (2012) Characterisation of metal-complexing membranes prepared by the semiinterpenetrating polymer networks technique. Application to the removal of heavy metal ions from aqueous solutions. J. Chem. eng., 187, 16-28.

Cegłowski, M., and Schroeder, G. (2015) Preparation of porous resin with schiff base chelating groups for removal of heavy metal ions from aqueous solutions. J. Chem. Eng., 263, 402-411.

Celik, A., and Demirbas, A. (2005) Removal of heavy metal ions from aqueous solutions via adsorption onto modified lignin from pulping wastes. J. Energy source, 27, 1167-1177.

Crini, G. (2005) Recent developments in polysaccharidebased materials used as adsorbents in wastewater treatment. Progr. Polym. Sci., 30, 38-70.

Fan, H. T., Liu, J. X., Yao, H., Zhang, Z. G., Yan, F., and Li, W. X. (2013) Ionic imprinted silicasupported hybrid sorbent with an anchored chelating schiff base for selective removal of cadmium(II) ions from aqueous media. J.Ind Eng. \& Chem. Resear., 53, 369-378.

Fang, J. M., Fowler, P. A., Sayers, C., and Williams, P. A. (2004) Preparation and characteristics of phosphate monoesters sweet potato starch. J. Carbohy. polym., 55, 283-289.

Farajzadeh, M. A., and Monji, A. B. (2004) Adsorption characteristics of wheat bran towards heavy metal Cations, Journal of Separation \& Purification Technology, 38, 197-207.

Feizi, M., and Jalali, M. (2015) Removal of heavy metals from aqueous solutions using sunflower, potato, canola and walnut shell residues. Journal of Taiwan Institute Chemical Engineers, 54, 125-136.

Fiedorowicz, M., and Para, A. (2006) Structural and molecular properties of dialdehyde starch Journal of Carbohydrate Polymer, 63, 360-366.

Fu, F., and Wang, Q. (2011) Removal of heavy metal ions from wastewaters, Journal of environmental management, 92, 407-418
Gaya, U. I., Otene, E., and Abdullah, A. (2015) Adsorption of aqueous $\mathrm{Cd}$ (II) and $\mathrm{Pb}$ (II) on activated carbon nanopores prepared by chemical activation of doum palm shell. Springer open journal, 4(1), 1-18.

Hashem, M. A. (2007). Adsorption of lead ions from aqueous solution by okra wastes. International journal of physical science, 2, 178-184

Hofreiter, B. T., Alexander, B. H., and Wolff, I. A. (1955) Rapid estimation of dialdehyde content of periodate oxystarch through quantitative alkali consumption. Journal analytical chemistry, 27, 1930-1931

Ma, X., Liu, X., Anderson, D. P., and Chang, P. R. (2015) Modification of porous starch for the adsorption of heavy metal ions from aqueous solution. Journal of food chemistry, 181, 133139.

Mano, J. F., Koniarova, D., and R.L., R. (2003) Effect of starh type on miscibility in poly(ethylene oxide). Journal of material science and engineering, 14, 127-135

Monier, M., Ayad, D. M., and D.A., (2012) Adsorption of $\mathrm{Cu}(\mathrm{II}), \mathrm{Cd}(\mathrm{II})$ and $\mathrm{Ni}(\mathrm{II})$ ions by cross-linked magnetic chitosan-2-aminopyridine glyoxal Schiff base. Journal of colloids and surfaces biointerfaces, 94, 250- 258

Namasivayam, C., and Ranganathan, K. (1995) Removal of $\mathrm{Pb}$ (II), $\mathrm{Cd}(\mathrm{II})$ and $\mathrm{Ni}(\mathrm{II})$ and mixture of metal ions by adsorption onto waste $\mathrm{Fe}(\mathrm{III}) /$ $\mathrm{Cr}$ (III) hydroxide and fixed bed studies, Journal of environmental technology, 16, 851860.

Salisu, A. A., Musa, H., Abba, H., and Kogo, A. A. (2013) Preparation and characterization of dialdehyde starch and its cross-linking with copper (II) ion, Journal of Chemical and Pharmaceutical Research, 5, 153-158.

Sun, C., Zhang, G., Qu, R., and Yu, Y. (2011) Removal of transition metal ions from aqueous solution by crosslinked polystyrene-supported bis-8oxyquinoline-terminated open-chain crown ethers, Journal of chemical engineering, 170, 250-257.

Xiong, C., and Yao, C. (2009) Synthesis, characterization and application of triethylenetetramine modified polystyrene resin in removal of mercury, cadmium and lead from aqueous solutions. Journal of chemical engineering 155, 844-850.

Yang, L., Li, Y., Jin, X., Ye, Z., Ma, X., Wang, L., et al. (2011) Synthesis and characterization of a series of chelating resins containing amino/imino-carboxyl groups and their adsorption behavior for lead in aqueous phase. Journal of chemical engineering, 168, 115-124.

Yin, Q., Ju, B., Zhang, S., Wang, X., and Yang, J. (2008) Preparation and characteristics of novel dialdehyde aminothiazole starch and its adsorption properties for $\mathrm{Cu}$ (II) ions from aqueous solution, Journal of carbohydrate polymers, $72(2), 326-333$

Zhang, L., Liu, P., Wang, Y., and Gao, W. (2011) Study on physico-chemical properties of dialdehyde yam starch with different aldehyde group contents. Journal of thermochimica acta, 512, 196-201.

Zhang, S. D., Zhang, Y. R., Zhu, J., Wang, X. L., Yang, K. K., and Wang, Y. Z. (2007) Modified corn starchs with improved comprehensive properties for preparing thermoplastics StarchStark, New York: Wiley-Inrterscience, 59, 258268. 